\title{
The importance of glacier and forest change in hydrological climate-impact studies
}

\author{
N. Köplin ${ }^{1,2}$, B. Schädler ${ }^{1,2}$, D. Viviroli ${ }^{1,2}$, and R. Weingartner ${ }^{1,2}$ \\ ${ }^{1}$ Institute of Geography, University of Bern, Switzerland \\ ${ }^{2}$ Oeschger Centre for Climate Change Research, University of Bern, Switzerland
}

Correspondence to: N. Köplin (nina.koeplin@web.de)

Received: 26 April 2012 - Published in Hydrol. Earth Syst. Sci. Discuss.: 9 May 2012

Revised: 10 January 2013 - Accepted: 12 January 2013 - Published: 11 February 2013

\begin{abstract}
Changes in land cover alter the water balance components of a catchment, due to strong interactions between soils, vegetation and the atmosphere. Therefore, hydrological climate impact studies should also integrate scenarios of associated land cover change. To reflect two severe climate-induced changes in land cover, we applied scenarios of glacier retreat and forest cover increase that were derived from the temperature signals of the climate scenarios used in this study. The climate scenarios were derived from ten regional climate models from the ENSEMBLES project. Their respective temperature and precipitation changes between the scenario period (2074-2095) and the control period (1984-2005) were used to run a hydrological model. The relative importance of each of the three types of scenarios (climate, glacier, forest) was assessed through an analysis of variance (ANOVA). Altogether, 15 mountainous catchments in Switzerland were analysed, exhibiting different degrees of glaciation during the control period $(0-51 \%)$ and different degrees of forest cover increase under scenarios of change (12-55\% of the catchment area). The results show that even an extreme change in forest cover is negligible with respect to changes in runoff, but it is crucial as soon as changes in evaporation or soil moisture are concerned. For the latter two variables, the relative impact of forest change is proportional to the magnitude of its change. For changes that concern $35 \%$ of the catchment area or more, the effect of forest change on summer evapotranspiration is equally or even more important than the climate signal. For catchments with a glaciation of $10 \%$ or more in the control period, the glacier retreat significantly determines summer and annual runoff. The most important source of uncertainty in this study, though, is the climate scenario and it is highly recommended to apply an
\end{abstract}

ensemble of climate scenarios in the impact studies. The results presented here are valid for the climatic region they were tested for, i.e., a humid, mid-latitude mountainous environment. They might be different for regions where the evaporation is a major component of the water balance, for example. Nevertheless, a hydrological climate-impact study that assesses the additional impacts of forest and glacier change is new so far and provides insight into the question whether or not it is necessary to account for land cover changes as part of climate change impacts on hydrological systems.

\section{Introduction}

Changes in land use and land cover alter the hydrology of a catchment through changes in evapotranspiration (e.g., Cuo et al., 2009; Dunn and Mackay, 1995; Klöcking and Haberlandt, 2002; Lahmer et al., 2001; Zierl and Bugmann, 2005) and altered surface roughness and soil properties, which modify the runoff generation and concentration processes (Hundecha and Bárdossy, 2004).

In addition to anthropogenic land modifications, the vegetation itself responds to changes in climate with species movement or redistribution and phenological changes (Leuzinger, 2009; Schumacher and Bugmann, 2006; Theurillat and Guisan, 2001). In a mountainous environment, for example, increasing temperatures result in an upward movement of the tree line because the tree line is a climatically determined ecotone (Dullinger et al., 2004). Another climateinduced change in land cover is glacier retreat. Glaciers, however, constitute a special case of land cover since they produce runoff themselves from previously stored water. 
The rapid and severe global glacier retreat due to the past increase in temperature is very well documented (see e.g., Arendt et al., 2002; Dyurgerov and Meier, 1997; Paul et al., 2004) and easy to comprehend. Concerning the increase in tree line it is often argued that trees are incapable of responding to changed environmental conditions within rather short time periods like, for example, less than a century (Dullinger et al., 2004; Egli et al., 2008; Theurillat and Guisan, 2001). This is assumed because other environmental factors than temperature, such as a low soil-moisture in shallow alpine soils, could prevent rapid upslope migration of trees (Henne et al., 2011). On the other hand, paleoecological records provide evidence for a rapid upslope (and downward) movement. Tinner and Theurillat (2003), for instance, who analysed pollen in lake sediment cores from study sites in southwest Switzerland, concluded that the tree line in this region fluctuated during the past $11500 \mathrm{yr}$, and Tinner and Lotter (2001) showed that these fluctuations can be attributed to climatic change, i.e., to increases and decreases in temperature. Moreover, Tinner and Kaltenrieder (2005) demonstrated that, during the Holocene, "[...] vegetation was in dynamic equilibrium with climate, [and] forecasted global warming may trigger rapid upslope movements of the tree line of up to $800 \mathrm{~m}$ within a few decades or centuries [...]".

These observed and anticipated changes in forest cover in Switzerland are not only a result of climate change, but also a result of altered land use practices. Gehrig-Fasel et al. (2007), for example, found an increase in forest cover in the Swiss Alps for the very short period from 1985 to 1997 . They attributed this increase to both the change in climate and in land use, the latter of which being primarily land abandonment of unprofitable high elevated areas. Gehrig-Fasel et al. (2007) found land use change to be most important for the observed increases in forest cover. Though, they expect climate change to gain in importance for the 21 st century.

Most studies assessing the impacts of climate change on hydrological systems neglect the effects of accompanied changes in forest cover (see e.g., Elsner et al., 2010; Gunawardhana and Kazama, 2012; Laghari et al., 2012). Only few studies assessed its impact in an alpine (e.g., Zierl and Bugmann, 2005) or pre-alpine, mid-latitude environment (Gasser et al., 2003). This is somewhat different regarding the effects of glacier retreat. Most recent hydrological climate impact studies account for glacier retreat as an intrinsic component of climatic and hydrological change (e.g., Hänggi, 2011; Horton et al., 2006; Schaefli et al., 2007). Fewer studies, however, particularly assess its net-effect on the projected runoff (Finger et al., 2012; Huss et al., 2008; Jost et al., 2012; Stahl et al., 2008) and further information on this topic is needed. Generally, there is a growing consensus in the scientific community that land cover impacts have to be accounted for in climate impact studies to reliably assess future availability of water resources (e.g., Bronstert, 2004; Hejazi and Moglen, 2008; Viviroli et al., 2011).
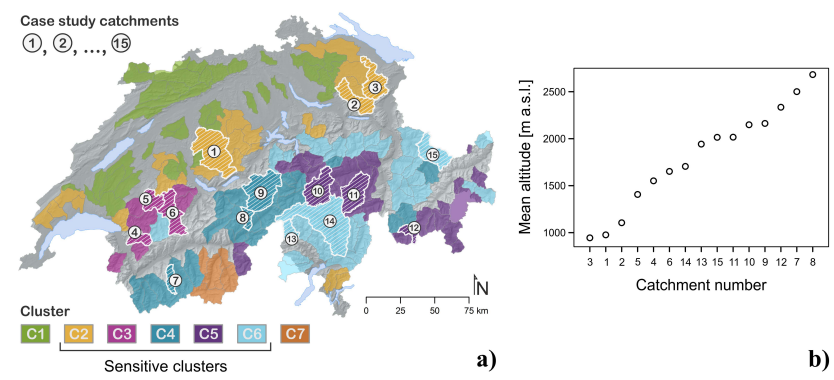

Fig. 1. Spatial (a) and altitudinal (b) distribution of case study catchments. The clustering according to Köplin et al. (2012) is displayed. Out of the seven clusters, C2 to C6 showed the most sensitive response to climate change in the study by Köplin et al. (2012) and we sampled those five sensitive clusters through three catchments each, which results in 15 case studies for further analysis.

Given that the forest and glacier area in Switzerland might change considerably, the question is to what extend this change would alter the projected hydrological change caused by changes in climate? Or more specifically, how do the relative changes that are introduced by an altered glacier runoff and a changed forest cover compare to the relative impact of the climate signal itself? These questions are answered in this study by means of hydrological climate-impact modelling in 15 mesoscale catchments in Switzerland. The study provides insight into the question whether or not it is necessary to account for glacier and forest cover changes as part of climate change impacts on hydrological systems.

\section{Study area and data}

We extended an earlier study by Köplin et al. (2010, 2012) where we modelled and analysed a comprehensive set of 186 mesoscale catchments in Switzerland with respect to hydrological change. We applied the output of ten regional climate models (RCMs) as well as scenarios of glacier retreat to run the hydrological modelling system PREVAH (Viviroli et al., 2009a) and to determine climate-change sensitive regions in Switzerland. Here, we used the same model set up with respect to the RCMs, the glacier retreat and the hydrological model, but extended it by applying three different forest change scenarios (cf. Sect. 2.3). Although climate scenario data for two periods (2025-2046 and 2074-2095) in the 21st century were available, we only assessed the so called farfuture period at the end of the century. This is to account for ecological time lags of a few decades (Harsch et al., 2009) that will likely prevent significant tree growth until the nearfuture period.

We analysed the hydrological impacts of climate change together with its accompanying forest increase and glacier retreat in a sample of 15 case study catchments in Switzerland (Fig. 1). The catchments are representative of the different regions in Switzerland that are particularly sensitive to 
climate change as defined in Köplin et al. (2012): each sensitive region (C2 to C6 in Fig. 1a) is represented by three case study catchments. Moreover, the case study catchments evenly cover an altitudinal range from 1000 to $2600 \mathrm{~m}$ a.s.l. (Fig. 1b). Catchments located within this range are specifically sensitive to changes in temperature, which was demonstrated by Köplin et al. (2012). Since the land cover scenarios in this study solely depend on temperature change (cf. Sects. 2.2 and 2.3), the selected catchments constitute a suitable sample for our study.

The hydrological model parameters for the study catchments were regionalised from calibrated parameter sets. We will briefly summarise this procedure in the following, for further details see Köplin et al. (2010, 2012) and Viviroli et al. $(2009 \mathrm{~b}, \mathrm{c})$. Altogether, 12 tuneable model parameters (14 for glaciated catchments) were calibrated for every catchment using an iterative search algorithm (Viviroli et al., 2009b). Then, a regionalisation procedure was applied because most of the catchments in the high alpine area are used for hydropower production and can, therefore, not be calibrated on measured natural runoff data. The runoff for those high alpine catchments is regionalised by combining seven different hydrographs that are representative for a given catchment: five hydrographs derived through Nearest Neighbours, one hydrograph derived through Kriging and one through Regression (Viviroli et al., 2009c). The seven hydrographs are combined by computing the mean of the discharge values for every time step (i.e., per every hour). Applying this regionalisation procedure means that we study the natural runoff behaviour of the catchments under scenarios of climate and land cover change neglecting the influence of hydropower production, which should be kept in mind when interpreting the results.

\subsection{Climate scenarios}

The climate scenarios are part of the Swiss climate change scenarios CH2011 (2011). They were provided for the meteorological variables temperature and precipitation and are based on the Delta Change approach. Bosshard et al. (2011) applied this downscaling procedure to ten RCMs from the ENSEMBLES-project (van der Linden and Mitchell, 2009), all of them assuming the A1B emission scenario and driven by 5 different GCMs. In this study, the climate change signals between a scenario period at the end of the 21st century (2074-2095) and the control period (1984-2005) were used. The novelty introduced to the downscaling procedure by Bosshard et al. (2011) is a spectral smoothing method to filter the annual cycle of daily changes, yielding a continuous representation of the annual cycle of climate change signals. The specific mean annual cycles of temperature and precipitation change were provided for every meteorological station in Switzerland, i.e., for 188 temperature and 565 precipitation stations (CH2011, 2011).
To run the hydrological model with these climate scenarios, we first scaled the observed precipitation and temperature time series of every meteorological station with the station-specific annual cycle of daily change values. Then, the scaled time series were interpolated to the catchment scale with a spatial resolution of $500 \times 500 \mathrm{~m}^{2}$. Afterwards, the spatially distributed climate data was averaged to $100 \mathrm{~m}$ elevation zones. See also Köplin et al. (2010) for a detailed description of the interpolation of climate input data to the catchment scale.

Because the climate scenarios are based on the Delta Change approach that assesses changes in the long-term mean annual cycle of the climate variables, all of the subsequent analyses of hydrological response variables are based also on the mean annual cycle (i.e., mean monthly, seasonal and annual values, respectively). This post-processing method does not account for changes in the variability of the climate variables, though, which might be a strong simplification.

The projected climate change for the case study catchments can be summarised as follows: the ensemble mean projects temperature increases during the whole year with the most pronounced increase in summer $(4 \mathrm{~K})$ and a smaller increase in spring $(2.8 \mathrm{~K})$. The winter precipitation increases by $10 \%$ on average, whereas summer precipitation decreases by $20 \%$ and spring as well as autumn precipitation do not show a distinct change signal (see Bosshard et al., 2011 and CH2011, 2011 for more details).

To derive the scenarios of glacier retreat (Sect. 2.2) and forest cover increase (Sect. 2.3), the ten climate scenarios were assigned to three groups of different temperature increases (a low, a moderate and a high increase, cf. Table 1). For every catchment, the mean annual delta $T$ was calculated and those values were then averaged within a group so that each catchment has a specific low, moderate and high delta $T$. Depending on these temperature increases, three different scenarios of glacier retreat were calculated (Linsbauer et al., 2013, Sect. 2.2) as well as three different forest extents per forest scenario (Sect. 2.3). For every hydrological model-run forced with a certain climate scenario (i.e., with one of the group low, moderate or high $T$ increase), the appropriate glacier and forest scenarios were chosen (i.e., low, moderate or high).

\subsection{Glacier retreat}

The glacier scenarios are calculated as a function of the climate scenarios' temperature changes using a glacier retreat model (Linsbauer et al., 2013; Paul et al., 2007, 2011). The glacier retreat model is based on alterations of the glaciers' equilibrium line altitude (ELA). The ELA is the altitude at which the mass balance of a glacier equals zero or in other words, where accumulation equals ablation (Paul et al., 2007), and it rises with increasing temperature. In the model 
Table 1. Annual delta $T$ and $P$ for every climate model chain. The mean (MEAN), minimum (MIN) and maximum (MAX) values characterise the distribution of the catchment-specific annual change values. The precipitation change signal is given for additional information, but the grouping of climate model chains to the three different classes of mean annual temperature increase (low, moderate, high) is solely based on delta $T$.

\begin{tabular}{lrrrrrrl}
\hline Climate model name & Delta $T$ & & & Delta $P$ & & T-increase \\
\hline (Institution_GCM_RCM) & Mean & Min & Max & Mean & Min & Max & grouping \\
\hline SMHI_BCM_RCA* & 2.3 & 1.9 & 2.6 & 0.98 & 0.89 & 1.07 & low* \\
DMI_ECHAM5_HIRHAM & 2.6 & 2.0 & 2.9 & 1.00 & 0.94 & 1.04 & low \\
ICTP_ECHAM5_REGCM & 2.9 & 2.8 & 3.0 & 1.03 & 0.98 & 1.08 & low \\
CNRM_ARPEGE_ALADIN & 3.0 & 2.7 & 3.4 & 0.91 & 0.88 & 0.95 & moderate \\
SMHI_HadCM3Q3_RCA & 3.3 & 2.9 & 3.6 & 1.07 & 1.03 & 1.13 & moderate \\
KNMI_ECHAM5_RACMO* & 3.3 & 3.1 & 3.5 & 1.04 & 0.93 & 1.12 & moderate* \\
MPI_ECHAM5_REMO & 3.4 & 3.1 & 3.9 & 1.03 & 1.00 & 1.06 & moderate \\
SMHI_ECHAM5_RCA & 3.4 & 2.9 & 3.8 & 0.99 & 0.94 & 1.07 & moderate \\
ETHZ_HadCM3Q0_CLM & 3.9 & 3.7 & 4.0 & 0.96 & 0.89 & 1.08 & high \\
HC_HadCM3Q0_HadRM3Q0* & 4.2 & 4.0 & 4.4 & 0.95 & 0.93 & 0.99 & high* \\
\hline
\end{tabular}

* These three climate model chains are applied in the ANOVA.

of glacier retreat, the equilibrium line is defined to rise $150 \mathrm{~m}$ per $1 \mathrm{~K}$ (Linsbauer et al., 2013).

In the Swiss Alps, the glacier area above the ELA, the accumulation zone of a glacier, comprises $60 \%$ of the total glacier area, on average (MBB, 2005; Paul et al., 2007). An increase of the ELA entails adaptation of the glacier to the altered condition until the ELA divides the glacier at a ratio of 40 to $60 \%$ again. This adaptation occurs delayed over a longer time period whereas the ELA immediately reacts on altered temperatures. The delayed adaptation, i.e., the response time of a glacier, is specific for every glacier and is at $10-40 \mathrm{yr}$ for most glaciers in the Swiss Alps and 50-100 yr for the thickest and largest ones (Paul et al., 2011). In the model applied here, a mean response time of $50 \mathrm{yr}$ is assumed, whereas the shift of the ELA is calculated with the low, moderate and high temperature changes.

In our study, the surface that is revealed when a glacier retreats is defined as rock because it is assumed that soil formation takes much longer than only $100 \mathrm{yr}$, i.e., it is not completed in the time period from the control to the scenario period. The glacier change (GC), i.e., the retreat per catchment from the control to the scenario period is depicted in Fig. 2. It has to be stated that the glacier retreat assumed in this study is rather conservative because the model does not take into account enhanced input of dust or lake formation, for example, which would accelerate glacier retreat. Based on the latest observed temperature increase and considering positive feedbacks, the glacier retreat would be more severe than calculated with the present model (Linsbauer et al., 2013). Nevertheless, these glacier scenarios constitute a unique data basis for our study since they comprehensively assess the glacier retreat for the entire Swiss Alps.

For the analysis of variance (Sect. 3.2), we added an extreme glacier scenario to the setup, where we removed all glaciers from the catchments $\left(\mathrm{G}_{\mathrm{NO}}\right)$. This represents one pos- sibility to assess the relative impact of glacier retreat on the projections if no specific retreat scenarios were available. Moreover, we thereby cover the whole range of possible glacier extents, from the control period extent to a complete glacier-free state: as mentioned above, the scenarios of glacier retreat have to be considered being rather conservative, and most of the smaller glaciers in our study could possibly have disappeared at the end of the century. Furthermore, it is worth noting that the glacier scenarios are ad-hoc as well as they are static. That is, for the scenario simulations the glacier area has changed from the beginning, and there is no gradual glacier retreat during the modelling period.

\subsection{Forest scenarios}

In this study, vegetation change is defined as an increase of forest cover due to both the increase of the tree line and land abandonment. We narrowed down vegetation change to a change in forest cover, because the conversion of any vegetation into forest constitutes a drastic change in land cover and presumably causes the strongest hydrological signal, due to the strong increase of the interception storage, for example.

Our simple forest change model comprises different rules that control tree growth: Trees can only grow where the former land cover was bush, pasture, sub-alpine meadow, alpine meadow, alpine vegetation, rough pasture or bare soil vegetation, but they cannot grow on rock, urban areas, water and wetlands, for obvious reasons. Areas used for agriculture are excluded from forest expansion, too, because these areas are protected by law in Switzerland since 1992 (Lüscher, 2004). Furthermore, trees can only grow on areas with a slope of less than $40^{\circ}$ because steeper slopes unlikely support higher vegetation (Theurillat and Guisan, 2001).

Temperature is the most important factor determining plant growth (Körner, 2007), since it controls, i.e., promotes 

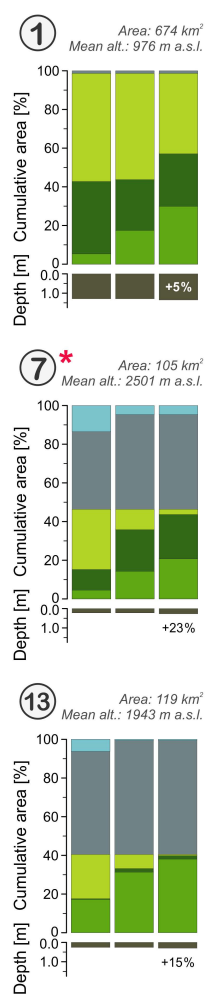
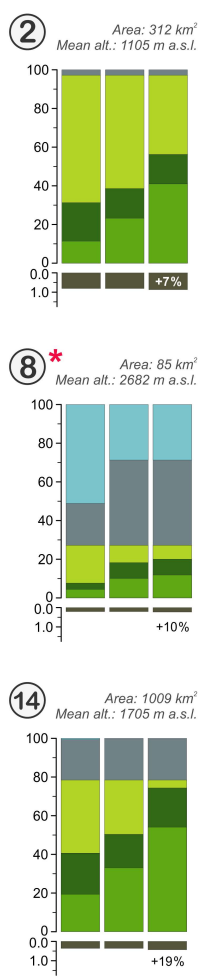
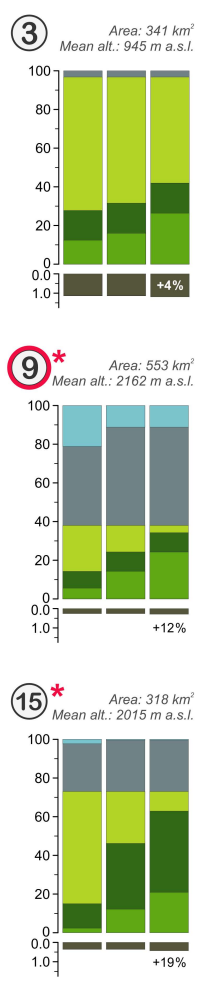
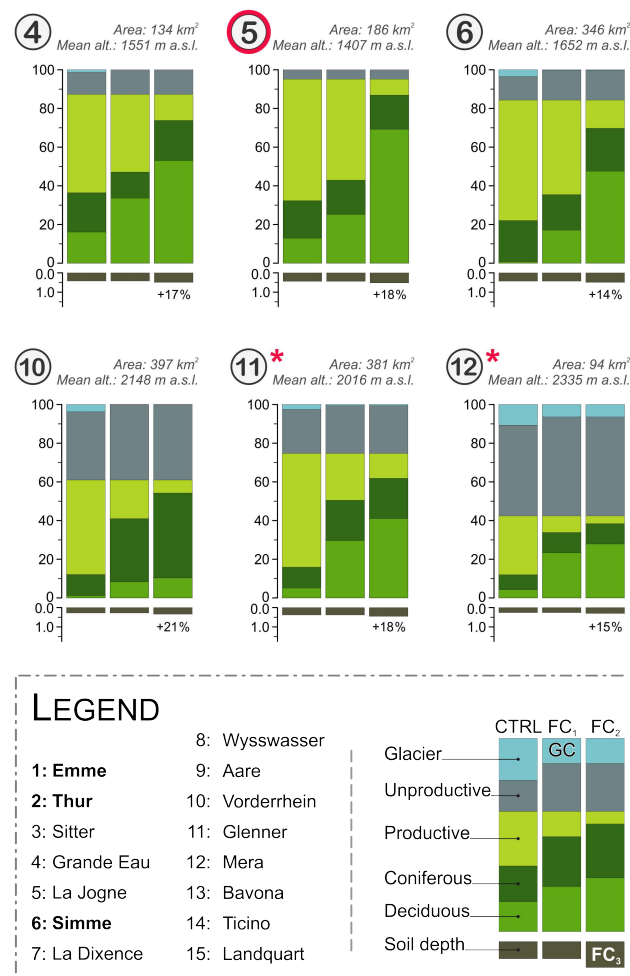

Fig. 2. Relative proportion of glacier, unproductive, productive and coniferous and deciduous forest area per catchment, as well as proportional increase of the catchments' mean soil depth. Unproductive area subsumes water bodies, urban area and rock; productive area comprises all vegetational land covers except for forest. The left column of each catchment-panel visualises the control period's proportional land covers (CTRL), the middle column those for both glacier retreat $(\mathrm{GC})$ and tree line increase $\left(\mathrm{FC}_{1}\right)$, the right column depicts additional land abandonment $\left(\mathrm{FC}_{2}\right)$ and soil genesis $\left(\mathrm{FC}_{3}\right)$, the latter shown on the lower right bar. Please note that only the mean glacier and forest extents are shown and not the extents corresponding to a low and high temperature increase (cf. also Sect. 2.1.1). The names of the catchments' main channels are given in the legend, for the respective locations please see Fig. 1. The catchments highlighted in bold font are not influenced by hydropower production, whereas the discharge of all other catchments is more or less strongly affected. The catchments marked with a red circle are analysed for changes of the water balance components (Sect. 4.1); the catchments marked with a red asterisk are used in the ANOVA (Sect. 4.3).

and limits tree growth (Grace et al., 2002). This is why we calculated potential scenario tree lines based on mean annual temperature increases of the ten climate scenarios in use and without accounting for changes in precipitation. The increase in tree line was calculated according to the average temperature lapse rate of $0.56 \mathrm{~K}$ per $100 \mathrm{~m}$ (Körner, 1998; Theurillat and Guisan, 2001). First the upper tree line of the control period was determined for every catchment. Then the catchment-specific low, moderate and high temperature increase (cf. Sect. 2.1.1) was used to calculate the potential scenario tree line. For a climate scenario with a low temperature increase (e.g., $2.6 \mathrm{~K}$ ), the scenario tree line would be $465 \mathrm{~m}$ higher than the actual catchment-specific control period's tree line $(2.6 \mathrm{~K} / 0.56 \mathrm{~K} \times 100 \mathrm{~m})$.

Based on the outlined forest scenario constraints, we defined three different forest scenarios which we briefly describe in the following. Attention should be paid to the consecutive setup of the scenarios (see Table 2 for a summary): each scenario incorporates the changes of the pre- viously introduced scenario, i.e., the second forest change $\left(\mathrm{FC}_{2}\right)$ integrates the changes of the first forest scenario $\left(\mathrm{FC}_{1}\right)$ whereas the third $\left(\mathrm{FC}_{3}\right)$ inherits the changes from both $\mathrm{FC}_{1}$ and $\mathrm{FC}_{2}$. All three forest scenarios, on the other hand, integrate glacier retreat (GC), and all four land cover scenarios are run with the climate scenario input (CC), of course.

The first forest scenario $\mathrm{FC}_{1}$ represents tree line increase, where deciduous and coniferous forests are treated separately, because of their specific natural tree lines. First, the coniferous forest grows beyond its control period tree line on the allowed areas specified above and rises up to the scenario treeline, i.e., it is purely an upwards expansion. Then, the deciduous forest grows above its control period tree line and on the same allowed areas. Deciduous forest, however, can also replace coniferous forest. This first scenario of forest change thereby reflects findings from Leuzinger (2009) who assumes that the tree line in Switzerland will increase significantly and deciduous forest will replace the formerly dominating coniferous forest. It has to be stated, though, that 
Table 2. Nomenclature of scenario combinations for the descriptive analysis (cf. also Fig. 4, upper half). CTRL always corresponds to the control period from 1984-2005, each scenario is valid for the scenario period from 2074-2095. Note the successive structure of the scenario combinations: per scenario just one member in the chain is changed.

\begin{tabular}{lcccl}
\hline Name & Climate change & Glacier change & Forest change & Description \\
\hline CTRL & $\mathrm{C}_{\mathrm{CTRL}}$ & $\mathrm{G}_{\mathrm{CTRL}}$ & $\mathrm{F}_{\mathrm{CTRL}}$ & $\begin{array}{l}\text { Baseline scenario with control period climate, glacier } \\
\text { and forest extent. }\end{array}$ \\
\hline $\mathrm{CC}_{\mathrm{EM}}$ & $\mathrm{CC}_{1}-\mathrm{CC}_{10}$ & $\mathrm{G}_{\mathrm{CTRL}}$ & $\mathrm{F}_{\mathrm{CTRL}}$ & $\begin{array}{l}\text { Climate change only. Note that for the descriptive } \\
\text { analyses the ten simulations (due to ten CCs, i.e., } \\
\text { RCMs) are averaged to the ensemble mean (EM). }\end{array}$ \\
\hline $\mathrm{GC}_{\mathrm{EM}}$ & $\mathrm{CC}_{1}-\mathrm{CC}_{10}$ & $\mathrm{GC}$ & $\mathrm{F}_{\mathrm{CTRL}}$ & $\begin{array}{l}\text { Additional glacier retreat. Again, the ten resulting } \\
\text { simulations (due to 10 CCs) are averaged to the EM. }\end{array}$ \\
\hline $\mathrm{FC}_{1, \mathrm{EM}}$ & $\mathrm{CC}_{1}-\mathrm{CC}_{10}$ & $\mathrm{GC}$ & $\mathrm{FC}_{1}$ & \begin{tabular}{l} 
Additional tree line increase, averaged to EM. \\
\hline $\mathrm{FC}_{2, \mathrm{EM}}$
\end{tabular} $\mathrm{CC}_{1}-\mathrm{CC}_{10}$ \\
\hline $\mathrm{FC}_{3, \mathrm{EM}}$ & $\mathrm{CC}_{1}-\mathrm{CC}_{10}$ & $\mathrm{GC}$ & $\mathrm{FC}_{2}$ & $\begin{array}{l}\text { Additional land abandonment (i.e., in addition to tree } \\
\text { line increase), averaged to EM. }\end{array}$ \\
\hline
\end{tabular}

some authors actually anticipate a shift of whole vegetation belts (e.g., Leuzinger, 2009; Theurillat and Guisan, 2001). For our forest scenario, however, existing trees remain in the lower ranges, which we attribute to the Swiss forest law from 1991 (WaG, 2008). This law protects forested areas and aims at preserving the forest in Switzerland in its area and spatial distribution. Therefore, the formerly forested area is not reduced.

The second forest change $\mathrm{FC}_{2}$ is additional land abandonment. Please note that only areas formerly used for alpine farming are abandoned in this scenario, e.g., sub-alpine meadows or pastures, not to be confused with the agricultural areas protected by law from abandonment (see above). Within the control period's range of lower and upper tree line, first the coniferous forest grows on the allowed areas, then deciduous forest grows and again replaces coniferous forest within the deciduous forest's tree line boundaries. That is, this scenario reflects a sideways forest expansion within the control period's tree line boundaries and in addition to the previous pure upwards expansion in $\mathrm{FC}_{1}$. Both $\mathrm{FC}_{1}$ and $\mathrm{FC}_{2}$ are based on the results of Gehrig-Fasel et al. (2007) who found that climate change causes upward shifts of the tree line, whereas land abandonment results in forest ingrowth.

The last scenario of forest change $\left(\mathrm{FC}_{3}\right.$, soil genesis) is not a further increase in forested area, but an additional increase in soil depth under forest cover. This increase in soil depth has to be distinguished from the slow soil formation on bare rocks mentioned in Sect. 2.2. Here, it is an increase in depth of existing soils on forested areas because of the high input of organic matter through trees. It is based on the results by Mavris et al. (2010) who found a distinct accumulation of soil organic matter within $150 \mathrm{yr}$ of exposure after glacier retreat and re-colonisation of higher plants at the
Morteratsch glacier in eastern Switzerland. We mimic this in our scenarios with an arbitrary general increase of soil depth by $10 \mathrm{~cm}$ in $100 \mathrm{yr}$ on forest covered areas, both new and existing forests. This leads to increases in the mean soil depth of the catchments between $4 \%$ where the previous mean soil depth was high $(>1 \mathrm{~m})$ and $23 \%$ where it was low before $(<0.25 \mathrm{~m})$.

The tree line scenarios of our study catchments for coniferous forest range from $1910 \mathrm{~m}$ a.s.l. where the control period's tree line was low (1490 $\mathrm{m}$ a.s.1.), to $2870 \mathrm{~m}$ a.s.1. where the calculated shift in tree line due to the high temperature increase was maximal $(780 \mathrm{~m})$. The relative area of deciduous and coniferous forest per scenario, as well as the relative increase in soil depth per study catchment can be examined in Fig. 2. As for the glacier scenarios, all forest scenarios are applied instantaneously and they are static.

\subsection{Land cover in PREVAH}

This section is based on the documentation of the hydrological modelling system PREVAH (Precipitation-RunoffEVAporation-Hydrotope based model, Viviroli et al., 2007, 2009a). The land cover in PREVAH includes water bodies, glaciers, rock, bare soil, urban areas and natural as well as cultivated vegetation. Altogether, 22 land cover types are defined with the following land cover specific variables that are parameterised a priori on a monthly basis: Surface roughness, which is represented by average vegetation height, root depth, minimal stomatal resistance, leaf area index (LAI), vegetation density, maximal interception storage and albedo. These vegetation-specific parameters are used, among others, to calculate potential evapotranspiration (ETP) after the Penman-Monteith equation (Monteith, 1975). The actual evapotranspiration (ETA) is then derived from ETP using 
adjustment factors, dependent on the actual moisture and vegetation as well as soil conditions. A good overview on the evaporation module is given in Gurtz et al. (1999) and in the model documentation of Viviroli et al. (2007).

It should be clearly stated that temperature and precipitation are the only variables that change in the climate scenario (Sect. 2.1). The temperature is used (among others, see above) to calculate ETP after the Penman-Monteith equation. It indirectly influences ETP through a number of variables that are calculated with the aid of temperature, for example, the saturated vapour pressure at actual temperature, the density of dry air, the latent evaporation heat and the net radiation (see Viviroli et al., 2007 for more details). Therefore, ETP changes in the scenarios, although relative humidity, global radiation and wind speed, which are also used to calculate potential evapotranspiration, are assumed not to change. For the latter three variables the control period's time series are applied, which is a rough simplification that might affect the reliability of the results. For ETA the precipitation change plays a major role because precipitation recharges the soil moisture storage (or not). Moreover, land cover specific parameters like albedo, leaf area index, vegetation height and minimum stomata resistance change with the changing land cover in the scenario. As stated above, those variables are used to assess ETA, which is why it is reasonable to assess the effect of a changed land cover due to changes in climate with this modelling setup. Please also see the Supplement (Tables S1 a and b as well as Figs. S1 and S2) that demonstrate the relative and absolute changes in ETP and ETA in the scenarios.

So, vegetation has a direct influence on interception (SI and EI; see Fig. 3), depletes the soil moisture storage (SSM) via transpiration (ESM) and, thereby alters ETA, which is a basic water balance component. Land cover, however, also modifies the maximum storage capacity of SSM: the storage's limit is defined vegetation-specific using plantavailable soil-moisture capacity, root depth and soil depth. That is, in our scenarios SSM is not only increased through the root depth of the increased forest cover, but also through the increased soil depth under $\mathrm{FC}_{3}$, of course. An increased forest cover increases ETA and SSM and, thereby acts as a sink for runoff through withdrawal of water from the runoff generation modules (SUZ, SLZ). That is, the forest scenarios have the potential to indirectly reduce runoff, in particular the quick runoff component (R0). This indirect influence of vegetation on runoff reflects the commonly recognised effect of afforestation.

In contrast to vegetation, glaciers have a direct influence on runoff as they generate runoff themselves through melt of previously stored water which is added to different runoff components (see Fig. 3, lower left corner). Therefore, glaciers are a source for water in addition to liquid precipitation and snow melt and have to be considered a special case of land cover. The area that is released by the glacier is converted into rock (cf. Sect. 2.2), which constitutes a dras-
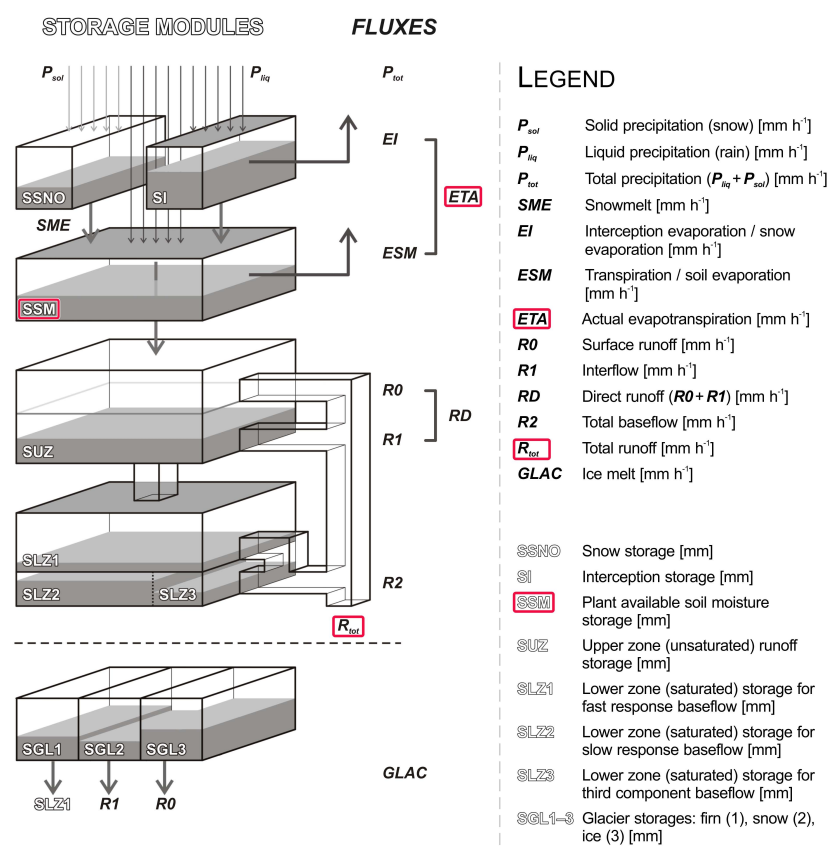

Fig. 3. Schematic of the modular model structure of PREVAH (modified after Viviroli et al., 2009a). The target variables analysed in this study are marked with red rectangles. Note that the model is driven by hourly input and, therefore, provides output in hourly resolution. For the analyses in this study the data are aggregated (cf. Sect. 3.1).

tic change: sublimation is reduced and, more important, the composition and amount of direct runoff (RD) is changed leading to an altered total runoff and a changed runoff behaviour.

As set out in this section, the hydrological modelling system PREVAH represents all important components that matter with respect to land cover change and its impact on hydrology, which is a prerequisite in this kind of impact study.

\section{Methods}

\subsection{Descriptive analysis}

We ran the hydrological model for all climate and land cover scenarios and then aggregated the hourly time series to the mean annual cycle of monthly values. Because we study changes in water balance components, these aggregated values are more meaningful. For ETA and $R_{\text {tot }}$ we computed the sum per month, and for SSM, being a state variable instead of a flux, we calculated the mean. For all analyses in this study, we used the R version 2.14.1 (R Development Core Team, 2011).

Please note that, for the descriptive analysis and each target variable, we computed the ensemble mean of the climate scenarios per land cover scenario (see also Table 2). That is, we aggregated the spread in the target variables that is 
caused by the different climate models to the mean value, here, to oppose this single $\mathrm{CC}_{\mathrm{EM}}$ value to the respective values for $\mathrm{GC}_{\mathrm{EM}}$ and $\mathrm{FC}_{1}, \mathrm{EM}-\mathrm{FC}_{3}$, EM as well as to the CTRL. The spread that is caused by the climate scenarios will be analysed in the ANOVA (Sect. 3.2).

\subsubsection{Comparison of water balance components}

First, we chose two very different catchments (La Jogne (5) and Aare (9), cf. Fig. 2) to study the possible range of changes in the water balance components due to the climate and land cover change. Catchment 5 shows both the strongest increase as well as the highest degree of forest cover under $\mathrm{FC}_{2}$ (CTRL: $32 \%$; $\mathrm{FC}_{2}: 87 \%$ ) and is not glaciated. On the other hand, catchment 9 shows the second lowest degree of forest cover under $\mathrm{FC}_{2}$ (34\%; CTRL: $14 \%$ ), the second highest relative glaciation $(21 \%)$ and the highest absolute glacier extent $\left(117 \mathrm{~km}^{2}\right)$ of all study catchments. The analyses are based on absolute values to ease the comparison between different water balance components; the results can be found in Sect. 4.1.

\subsubsection{Comparison of net changes between catchments}

Then, we analysed the net changes for the target variables actual evapotranspiration and total runoff both for the summer $\left(\mathrm{ETA}_{\mathrm{JJA}}, R_{\text {tot JJA }}\right)$ and the annual time scale $\left(\mathrm{ETA}_{\mathrm{a}}, R_{\mathrm{tot} \text { a }}\right)$. The net change is defined as the change in a target variable that is caused by one particular scenario and that is calculated relative to its preceding scenario. That is, the net change of $\mathrm{GC}_{\mathrm{EM}}$ (cf. Table 2) is calculated relative to the simulation of $\mathrm{CC}_{\mathrm{EM}}$, or the net change of $\mathrm{FC}_{2}$, EM is calculated relative to $\mathrm{FC}_{1, \mathrm{EM}}$. This relative calculation is necessary because every scenario incorporates the changes of its preceding scenarios as explained in Sect. 2.3.

We calculate the net changes per scenario and catchment to compare all 15 catchments and to analyse possible relations between the net change and the glacier retreat as well as the forest increase. For a strong forest increase, for example, one would expect a higher net change due to this forest change and compared to that of the climate and glacier changes. So, the net change allows to assess the relative importance one scenario has for the target variable and differs from the analysed absolute values mentioned in the previous section. The comparison of all catchments facilitates to distinguish systematic relationships between the relative importance and an associated degree of glaciation or forest cover, if at all measurable.

\subsection{Analysis of variance (ANOVA)}

To analyse the relative impacts of uncertainties in the three types of scenarios (climate, glacier, forest) on the target variables, we furthermore conducted an analysis of variance (ANOVA; see e.g., Doncaster and Davie (2007) for a comprehensive overview, which this section is based on). In the following, we explain how this analysis differs from the descriptive analysis above.

Through an ANOVA one can assess causal relationships between explanatory variables (the three types of scenarios) and a response variable (here one of ETA, SSM, $R_{\text {tot }}$ ). The explanatory variables can be of categorical scale and in the ANOVA terminology they are referred to as factors, whereas their numbers of categories are called levels. For example, the glacier scenarios constitutes a factor with three levels $\left(\mathrm{G}_{\mathrm{CTRL}}, \mathrm{GC}, \mathrm{G}_{\mathrm{NO}}\right.$; cf. Sect. 2.2). In contrast to the descriptive analysis above, which is more a qualitative comparison of the scenarios' effects (absolute and relative), the ANOVA facilitates to quantify the relative importance that uncertainties in the scenarios have for the variation in the target variables. It assesses whether the target variables' responses change for different levels of the factor. That is, an ANOVA decomposes the total variation of a target variable into variance fractions that can be ascribed to variation (i.e., uncertainty) in the factor variables' levels. The main advantage of this procedure is that the effects of various factors can be assessed simultaneously (and not separated as for the descriptive analysis), and, moreover, the effects of their interactions on the response can also be accounted for. Interactions are defined as effects of a factor that depend on the effects of one or more other factors.

To account for the interactions, the ANOVA design has to be a so called fully cross-factored design, which means that all possible scenario combinations are assessed (see Fig. 4). The three-factor cross-factored model in our study is then written as

$Y=C+G+F+I$

with $Y$ being the total variation of the response, $C$ being the variation explained through the climate scenarios, $G$ that explained through glacier change and $F$ that through forest change. The interaction term $I$ is defined as

$I=C \cdot G+C \cdot F+G \cdot F+C \cdot G \cdot F$

Because the ANOVA assesses the impact of various categorical factor variables simultaneously and accounts for their interactions, too, it is an ideal tool for the present analysis. This might also be the reason why it is increasingly used in hydrological climate-impact studies as a measure of uncertainty (see e.g., Bosshard et al., 2012; Finger et al., 2012; Rössler et al., 2012).

With the ANOVA, we analysed the annual cycles of monthly change signals of all target variables, separately. Because the different levels of the factors might influence the outcome of the ANOVA (i.e., a high proportion of variance explained might be an artefact of a high number of levels; it would be 10 for $\mathrm{CC}, 3$ for GC, 4 for FC), we reduced the setup to a $3 \mathrm{C} \times 3 \mathrm{G} \times 3 \mathrm{~F}$ matrix: the climate scenarios with the lowest, a moderate and the highest annual temperature increase (cf. Table 1) were combined with the three glacier extents $\left(\mathrm{G}_{\mathrm{CTRL}}, \mathrm{GC}, \mathrm{G}_{\mathrm{NO}}\right)$ and three of the four forest extents 


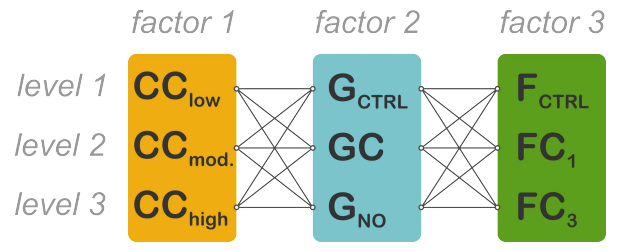

Fig. 4. Schematic of scenario coupling used in the ANOVA. The set of climate scenarios is reduced to three scenarios with a low, a moderate and a high temperature increase. The full range of glacier extents is assessed (from $\mathrm{G}_{\mathrm{CTRL}}$ to $\mathrm{G}_{\mathrm{NO}}$, cf. Sect. 2.2) and the forest change is represented by the control extent $\left(\mathrm{F}_{\mathrm{CTRL}}\right)$, the tree line increase only $\left(\mathrm{FC}_{1}\right)$ and the additional ingrowth and soil genesis $\left(\mathrm{FC}_{3}\right.$, cf. Sect. 2.3).

$\left(\mathrm{F}_{\mathrm{CTRL}}, \mathrm{FC}_{1}, \mathrm{FC}_{3}\right)$. The three climate scenarios are driven by three different GCMs. This setup involves that we sample the full range of uncertainties related to the glacier, a large range related to forest change and the full range related to the climate scenarios applied in this study. This full range of $\mathrm{CC}$, however, represents only a certain part of climate change, because the scenarios are based on just one emission scenario, for example. Hence, the CC variation in the ANOVA is very likely underestimated, which has to be considered interpreting the results. The fully cross-factored model also entails that physically unrealistic scenario combinations are assessed, for example, a high temperature increase combined with the glacier extent of the control period and the most extreme forest scenario. Still, we decided on this setup to assess the uncertainty that is introduced to the hydrological projections when not accounting for glacier retreat at all $\left(\mathrm{G}_{\mathrm{CTRL}}\right)$ or only simplistically accounting for the maximal impact $\left(\mathrm{G}_{\mathrm{NO}}\right)$. The same applies to the forest change: how much uncertainty would be introduced if one neglects forest change $\left(\mathrm{F}_{\mathrm{CTRL}}\right)$, if one takes account of an increase of the tree line alone $\left(\mathrm{FC}_{1}\right)$ or if one tries to reflect all possible changes (increase, ingrowth, soil genesis) that might occur $\mathrm{FC}_{3}$.

\section{Results}

\subsection{Comparison of water balance components}

The results for the two different case studies are displayed in Fig. 5 and summarised in Table 3. First the changes in catchment 5 (the pre-alpine case study) that are related to the climate scenarios are summarised and then compared to the additional changes in the target variables introduced through forest change. After that, the results for the high-alpine catchment 9 are described and compared to the previous catchment.

In catchment number 5, the increased temperature in the scenario period (cf. Table 3) leads to significantly increased liquid precipitation on the expense of solid precipitation and,

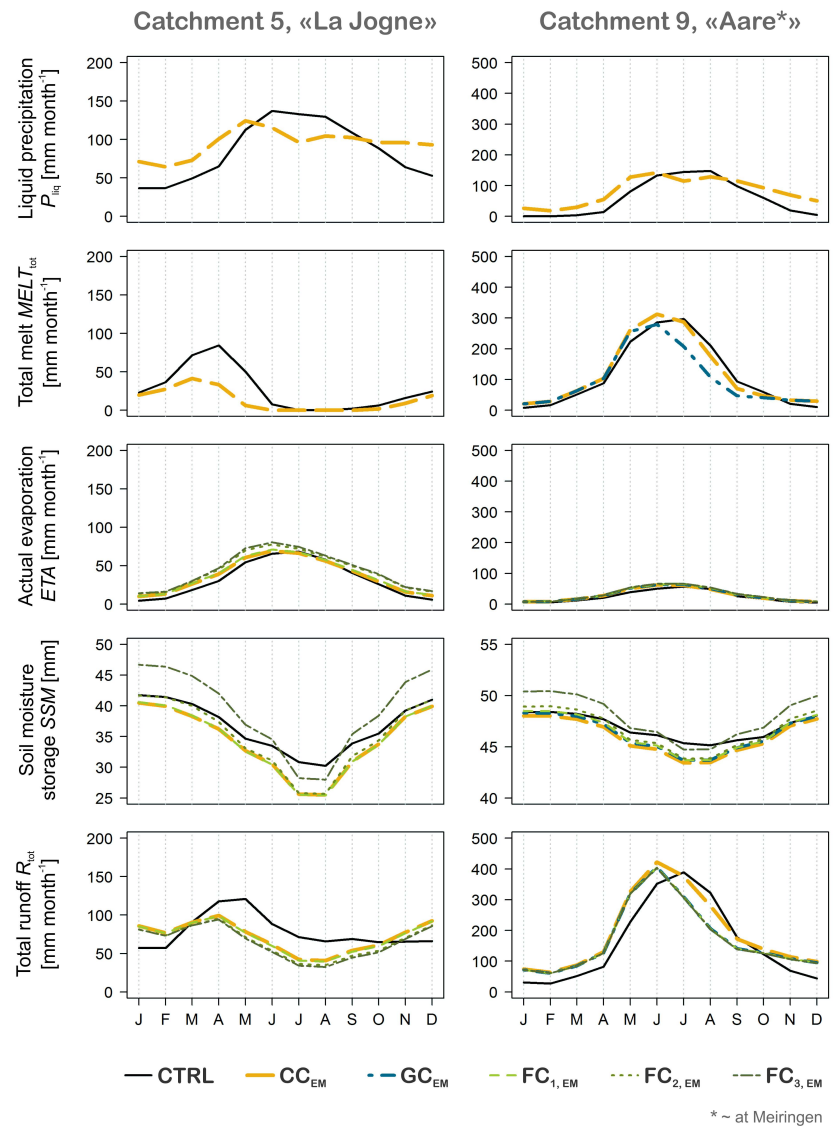

Fig. 5. Mean annual cycle of different water balance components ( $P_{\text {liq }}, \mathrm{MELT}_{\text {tot }}$, ETA, SSM, $R_{\text {tot }}$; rows 1 to 5 ) for the non-glaciated catchment La Jogne (No. 5, left column) and the glaciated catchment Aare (No. 9, right column). Total melt is the sum of snowand ice-melt, but only the glaciated catchment 9 has ice-melt, of course. For all curves except for that of the control period (CTRL), the ensemble mean is displayed $\left(\mathrm{CC}_{\mathrm{EM}}, \mathrm{GC}_{\mathrm{EM}}, \mathrm{FC}_{1}, \mathrm{EM}, \mathrm{FC}_{2}, \mathrm{EM}\right.$, $\mathrm{FC}_{3, \mathrm{EM}}$ ).

therefore, on the expense of snow melt. The decreased snow storage in the scenario period also affects the snow melt in spring (March-May; Fig. 5, left column), which is considerably reduced at the end of the century, as is the summer precipitation. The increased temperature furthermore leads to increased evapotranspiration (Table 3 and Fig. 5). In July and August, however, a slight decrease of actual evapotranspiration (ETA) is observed for climate change alone $\left(\mathrm{CC}_{\mathrm{EM}}\right)$. This indicates a limiting effect of the reduced precipitation in this season. This assumption is supported by the projected changes in soil moisture storage SSM which is significantly depleted during the summer months of the scenario period. For the variables ETA, SSM and $R_{\mathrm{tot}}$, the resulting curves for the forest changes are added to the plot. A slight effect of increasing forest cover can be observed for ETA: the monthly values increase with every scenario of forest change $\left(\mathrm{FC}_{1, \mathrm{EM}}-\mathrm{FC}_{3, \mathrm{EM}} ; \mathrm{Fig} .5\right)$, and these monthly changes add 
Table 3. Annual values of water balance components for catchments 5 (La Jogne) and 9 (Aare at Meiringen) shown in Fig. 5. The values in brackets are the changes in \% relative to the control period, except for temperature where it is the absolute change in K.

\begin{tabular}{|c|c|c|c|c|c|c|}
\hline Catchment 5, La Jogne & CTRL & $\mathrm{CC}_{\mathrm{EM}}$ & $\mathrm{GC}_{\mathrm{EM}}$ & $\mathrm{FC}_{1, \mathrm{EM}}$ & $\mathrm{FC}_{2}$, EM & $\mathrm{FC}_{3, \mathrm{EM}}$ \\
\hline$T\left[{ }^{\circ} \mathrm{C}\right]$ & 5 & $8(+3)$ & - & - & - & - \\
\hline$P_{\text {tot }}\left[\mathrm{mm} \mathrm{yr}^{-1}\right]$ & 1327 & $1304(-2)$ & - & - & - & - \\
\hline$P_{\mathrm{sol}}\left[\mathrm{mm} \mathrm{yr}^{-1}\right]$ & 335 & $165(-51)$ & - & - & - & - \\
\hline$P_{\text {liq }}\left[\mathrm{mm} \mathrm{yr}^{-1}\right]$ & 992 & $1139(+15)$ & - & - & - & - \\
\hline MELT $_{\text {tot }} *\left[\mathrm{~mm} \mathrm{yr}^{-1}\right]$ & 322 & $158(-51)$ & - & - & - & - \\
\hline ETP $\left[\mathrm{mm} \mathrm{yr}^{-1}\right]$ & 416 & $481(+16)$ & - & $488(+17)$ & $538(+29)$ & $552(+33)$ \\
\hline $\mathrm{ETA}\left[\mathrm{mm} \mathrm{yr}^{-1}\right]$ & 390 & $442(+13)$ & - & $455(+17)$ & $511(+31)$ & $528(+35)$ \\
\hline $\mathrm{SSM}[\mathrm{mm}]$ & 37 & $34(-6)$ & - & $34(-6)$ & $35(-4)$ & $39(+7)$ \\
\hline$R_{\text {tot }}\left[\mathrm{mm} \mathrm{yr}^{-1}\right]$ & 935 & $861(-8)$ & - & $847(-9)$ & $792(-15)$ & $774(-17)$ \\
\hline \multicolumn{7}{|c|}{ Catchment 9, Aare at Meiringen } \\
\hline$T\left[{ }^{\circ} \mathrm{C}\right]$ & 1 & $4(+3)$ & - & - & - & - \\
\hline$P_{\text {tot }}\left[\mathrm{mm} \mathrm{yr}^{-1}\right]$ & 2380 & $2359(-1)$ & - & - & - & - \\
\hline$P_{\text {sol }}\left[\mathrm{mm} \mathrm{yr}^{-1}\right]$ & 1600 & $1266(-21)$ & - & - & - & - \\
\hline$P_{\text {liq }}\left[\mathrm{mm} \mathrm{yr}^{-1}\right]$ & 780 & $1093(+40)$ & - & - & - & - \\
\hline $\operatorname{MELT}_{\text {tot }} *\left[\mathrm{~mm} \mathrm{yr}^{-1}\right]$ & 1364 & $1433(+5)$ & $1217(-11)$ & - & - & - \\
\hline ETP $\left[\mathrm{mm} \mathrm{yr}^{-1}\right]$ & 340 & $478(+41)$ & $484(+42)$ & $489(+44)$ & $497(+46)$ & $503(+48)$ \\
\hline $\mathrm{ETA}\left[\mathrm{mm} \mathrm{yr}^{-1}\right]$ & 297 & $353(+19)$ & $361(+21)$ & $368(+24)$ & $376(+27)$ & $383(+29)$ \\
\hline $\mathrm{SSM}[\mathrm{mm}]$ & 47 & $46(-2)$ & $46(-1)$ & $46(-1)$ & $47(0)$ & $48(+2)$ \\
\hline$R_{\text {tot }}\left[\mathrm{mm} \mathrm{yr}^{-1}\right]$ & 1897 & $2286(+21)$ & $2062(+9)$ & $2055(+8)$ & $2047(+8)$ & $2040(+8)$ \\
\hline
\end{tabular}

* MELT $_{\text {tot }}$ includes both snow- and glacier melt. Catchment 5 is not glaciated, therefore, there are no values in column GC, and MELT tot only represents snowmelt.

up over the year (Table 3). For SSM, the soil genesis scenario $\left(\mathrm{FC}_{3}, \mathrm{EM}\right)$ leads to a significantly increased soil moisture storage because the maximum storage capacity is, among others, defined via soil depth (cf. Sect. 2.4). Summer ETA, as a result, is significantly increased under this forest scenario, too. For the target variable $R_{\text {tot }}$, the annual cycle is clearly altered through the climate change signal, and the forest change scenarios follow this predefined annual cycle of the scenario period, in general. They lower the projected runoff slightly, though, which can be attributed to the increased ETA and SSM that constitute a withdrawal of water. The most extreme forest scenario $\mathrm{FC}_{3}$ lowers the runoff as much as the climate signal (Table 3). In summary, there is an effect of the extreme change in forest cover in this catchment, especially with respect to changes in ETA and SSM.

Catchment number 9, on the contrary, has an entirely different hydrological regime because of the differing mean altitudes of the catchments. The high alpine catchment 9 has a snow- and ice-fed regime with a typical peak in summer and a low flow season in winter (see Fig. 5, bottom-right panel). The increase in temperature causes an increase of liquid precipitation, but as opposed to catchment 5 it increases by $40 \%$. Due to the higher temperatures in the scenario period, the potential evapotranspiration is distinctly elevated. Actual evapotranspiration, however, does only increase half as much as ETP $(+19 \%$ opposed to $+41 \%$; cf. Table 3$)$. Evapotranspiration as a water balance component (and its change) is of minor importance in this catchment compared to catchment 5 : it comprises $12 \%$ of the mean annual catchment precipitation in the control period $\left(15 \%\right.$ for $\left.\mathrm{CC}_{\mathrm{EM}}\right)$. A net-increase in projected evapotranspiration under $\mathrm{FC}_{3}, \mathrm{EM}$ and relative to $\mathrm{GC}_{\mathrm{EM}}$ (i.e., the added net changes of $\mathrm{FC}_{1}, \mathrm{EM}^{-}$ $\mathrm{FC}_{3}$, EM) amounts to $+8 \%$. This increase in evapotranspiration leads to a decrease of total runoff by only $-1 \%$, however. The soil moisture storage SSM varies only marginally over the year and for the scenarios, with the exception of $\mathrm{FC}_{3}$, EM: the deeper soil causes slightly higher values for soil moisture in this scenario. For the target variable $R_{\text {tot }}$, a difference of the four land cover curves $\left(\mathrm{GC}_{\mathrm{EM}}, \mathrm{FC}_{1, \mathrm{EM}^{-}}\right.$ $\left.\mathrm{FC}_{3}, \mathrm{EM}\right)$ is hardly visible. Because the forest scenarios are added to the glacier change (cf. Sect. 2.3), this means forest change does not add a distinct signal to the projections and this change can be attributed to the glacier change, alone. The glacier retreat, in turn, has a pronounced effect on summer runoff through reduced ice melt. Not accounting for glacier retreat would, therefore, lead to a substantial overestimation of runoff in the melt season (June-September). This is particularly true if one considers that the glacier retreat might actually be more pronounced than it is in the scenarios applied here. The proportionately small forest extent and forest change in this catchment cannot further alter the projections that are strongly determined through climate and glacier change. 


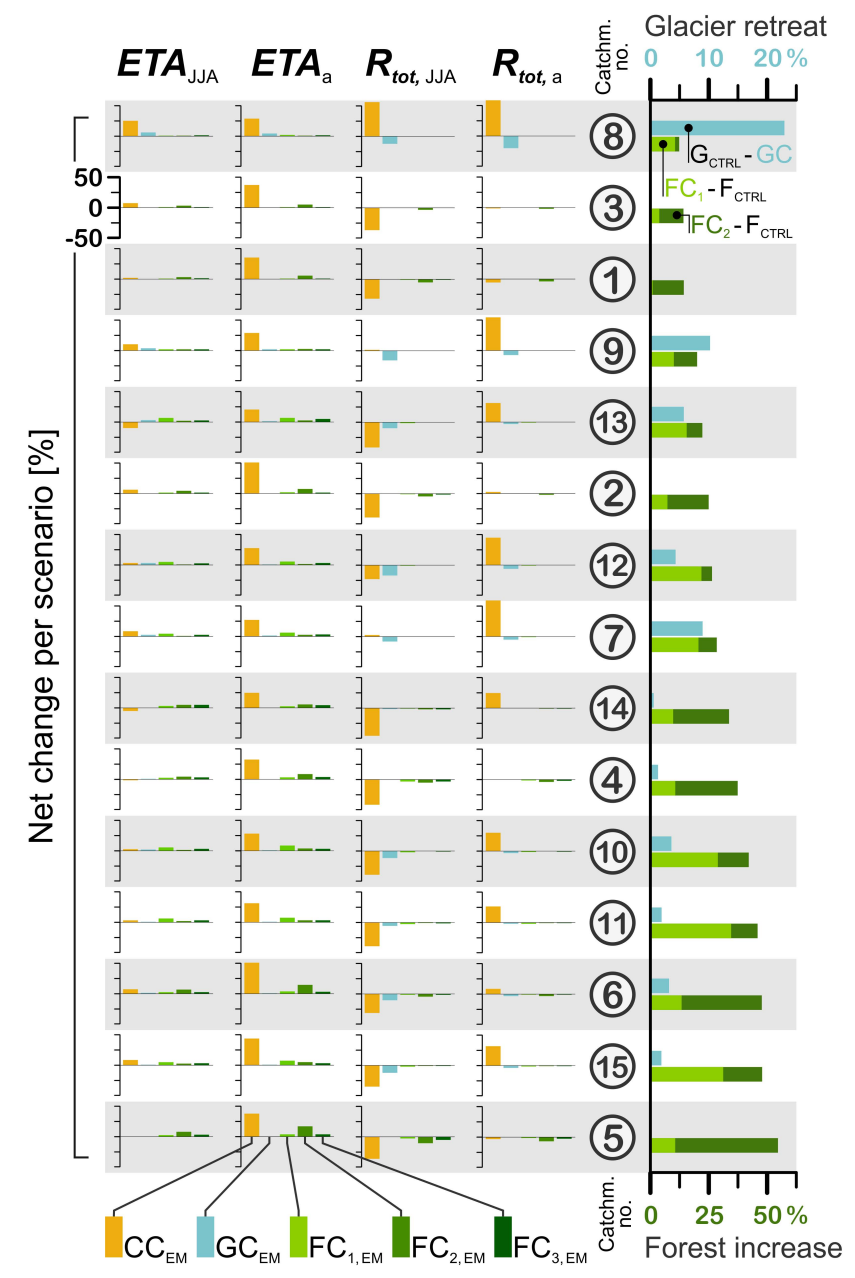

Fig. 6. Comparison of relative net changes per scenario $\left(\mathrm{CC}_{\mathrm{EM}}\right.$, $\left.\mathrm{GC}_{\mathrm{EM}}, \mathrm{FC}_{1}, \mathrm{EM}^{-}-\mathrm{FC}_{3}, \mathrm{EM}\right)$ and catchment. The first column (left) displays results for summer evapotranspiration (ETAJJA), the second those for annual evapotranspiration $\left(\mathrm{ETA}_{\mathrm{a}}\right)$, the third column depicts summer total runoff ( $\left.R_{\text {tot JJA }}\right)$, the fourth (right) annual total runoff $\left(R_{\text {tot a }}\right)$. The scale is the same for each panel, ranging from $-50-50 \%$ (indicated for ETAJJA, catchment 3 ). The catchments are sorted from top to bottom according to increasing forest change between CTRL and the combined forest increase of $\mathrm{FC}_{1}$ (light green bars) and $\mathrm{FC}_{2}$ (dark green bars), see right panel of the figure. The relative glacier retreat in per cent catchment area is added to the right panel, too (light blue bars).

Overall, the analysis of these two very different catchments indicates distinct influences of the forest and glacier change on the water balance components in addition to the changes caused by the climate scenarios. This additional influence of forest and glaciers, however, highly depends on the considered target variable and is either substantial or negligible. To study the effects of the degree of forest and glacier cover in more detail, we compared all catchments for the two target variables ETA and $R_{\text {tot }}$ in the next section.

\subsection{Comparison of net changes between catchments}

As set out in the methods section, increasing net changes with increasing changes in forest cover would indicate a causal relationship between the degree of forest cover change and its importance for the change in a target variable. Although there is no consistent pattern, this anticipated relationship can be observed for summer evapotranspiration (ETAJJA; Fig. 6, left column): in the lower part of the column, the net changes due to the three forest scenarios are equally or even more important than the climate and glacier change. Remarkable are catchments 13 and 14, where the net change of ETA due to the climate scenario is negative in summer, but it is converted into a positive signal under the most extreme forest change $\mathrm{FC}_{3}$ (when summing up the three forest net changes). This effect was observed for catchment 5 in the previous section, where the climate signal alone yielded slightly decreasing summer ETA, whereas it increased under forest change, particularly under $\mathrm{FC}_{3}$. This contrary signal in catchment 5 was attributed to the strong increase in soil moisture storage under forest change and, therefore, a higher amount of water available for evapotranspiration. Both catchments, nevertheless, show clear increases of annual ETA due to the climate scenarios. We know from the previous analysis that ETA increases during the whole year due to climate change except for the summer months, where decreasing precipitation limits actual evapotranspiration. In general, the annual ETA shows a similar, but less pronounced pattern of higher net changes with higher forest increase. The climate scenarios' net changes are dominating the change in ETA $_{\mathrm{a}}$, though. For the summer runoff as well as annual runoff ( $R_{\text {tot, JJA }}, R_{\text {tot, a }}$; third and fourth column), the forest net change is negligible, which underlines the findings from the previous analyses.

As opposed to the minor impact of forest change on the runoff, the glacier change has a noticeable effect on summer runoff. The net change of the glacier scenario slightly alters the annual runoff, too, but only for catchments where glacier retreat is substantial (e.g., 8, 9, 7, 12). However, the glacier net change never exceeds that of the climate scenario, with the exception of summer runoff of catchments 9 and 7 . Again, it has to be stated that the glacier effect might be more pronounced for more extreme scenarios of glacier retreat.

To summarise, the comparison of all catchments shows a discernible effect of forest change on summer evapotranspiration for catchments with a strong forest increase of at least $35 \%$ of the catchment area. To a smaller degree, this additional effect of forest change can be observed for annual ETA, too. Furthermore, the glacier retreat clearly alters summer runoff in addition to the climate scenario. Overall, however, the climate scenario largely dominates the changes in the assessed target variables. 


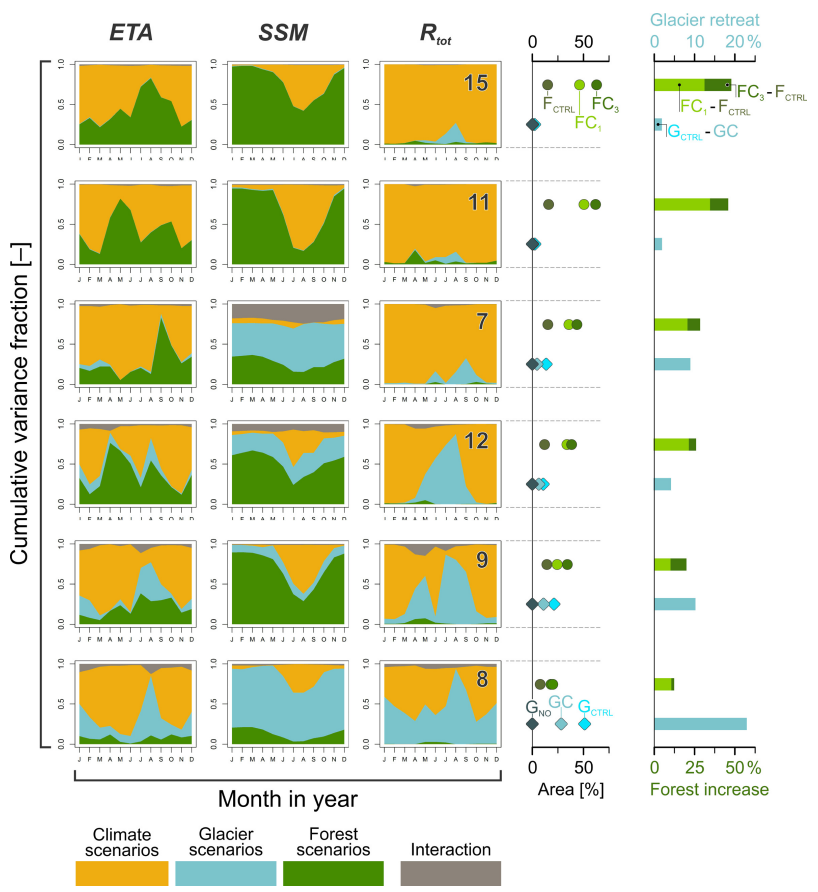

Fig. 7. ANOVA for the annual cycles of monthly change values per target variable ETA, SSM, $R_{\text {tot }}$. Each column shows the ANOVA results for one target variable and each row of three panels represents the results per catchment. The catchment number is indicated in the upper right corner of the respective right panel. The catchments are sorted from top to bottom according to decreasing forest change and increasing glacier retreat (except for catchments 7 and 12 where the order is twisted with respect to the glacier). The forest and glacier extents in percent catchment area are given for every catchment on the right side as well as the respective forest and glacier change.

\subsection{ANOVA}

The ANOVA results for the sample of six catchments (Fig. 7, rows) and the three target variables ETA, SSM and $R_{\text {tot }}$ (columns) can be studied per target variable from top to bottom or per catchment line by line. From top to bottom the degree of forest change decreases and glacier retreat increases. If there was a causal relationship between the degree of change in land cover and the respective variation in the target variable, the variance fractions of the forest scenarios should decrease from top to bottom, whereas the variance fractions of the glacier scenarios should increase in the same direction. For all panels, the interaction term is rather small which indicates that the variation in the target variables does not depend on combined effects of the scenarios. In other words, the respective variation can be unambiguously attributed to the variation in each of the single factors.

The abovementioned pattern, decreasing variance fraction for forest and increasing for glacier change from top to bottom, is particularly obvious for ETA: with decreasing forest change and increasing glacier retreat, the variance frac- tion that is attributed to forest change decreases whereas glacier change gains in relative importance. For each catchment, a clear annual cycle of the variance distribution with respect to ETA is observed: The relative importance of forest change, for example, is largest in late summer to autumn, which can be attributed to the minor importance of the climate scenario in this season (cf. Sects. 4.1 and 4.2) rather than to the superior importance of the forest scenario. The increasing variance fraction of glacier change with respect to ETA might seem surprising, but evaporation from snow and ice comprises a non-neglectable amount of the total catchment evapotranspiration in high-altitude catchments. Moreover, the forest change and, therefore, the relative importance of the forest scenarios is small in the highly glaciated catchments (cf. also catchments 8 and 9 in Fig. 6), which might additionally raise the variance fraction explained through glacier change. The major variance fraction in the less forested catchments arises from the climate scenario uncertainty, though.

The forest change does not add a significant variance to the target variable $R_{\text {tot }}$ which confirms our findings from the descriptive analyses. The relative importance of glacier change for this variable, in contrast, increases with glacier extent, which was also indicated by the previous results. As for ETA, the climate scenarios account for the major part of the variance of $R_{\text {tot }}$ also and the contribution of glacier change is only distinct in summer during melt season. The catchment with the highest range of glaciation (catchment 8 , bottom row in Fig. 7) shows a rather balanced variance fraction of around $30 \%$ during the whole year with a small peak during melt season.

The interpretation of the soil moisture storage SSM is less straightforward. Not only does this target variable lack a clear pattern of glacier and forest change, but also is the interaction term quite large for two of the six catchments. One pattern that recurs in five of six catchments, though, is the significant peak of the climate scenario's variance fraction in summer and the absence of the same during the rest of the year. This clear signal can be attributed to the pronounced temperature increase in summer and the associated depletion of SSM through evapotranspiration, but also to the decreasing summer precipitation and, therefore, a reduced input into the storage. An interesting feature can be observed comparing catchments 15 and 11: their change in forest cover is comparable, but the composition of deciduous and coniferous forest differs (cf. Fig. 2). For catchment 15, which has a higher proportion of coniferous forest, the variance fraction for SSM that is attributed to forest change is higher, too. The same applies for these two catchments and their ANOVA results for ETA. Obviously, the different parameterisations of deciduous and coniferous forest effect the variance distribution. The seemingly wrong order of catchments 7, 12 and 9 with respect to the variance distribution for SSM cannot be explained. 
The ANOVA results suggest that for catchments with a glaciation of $10 \%$ or more in the control period and a projected glacier retreat of more than $5 \%$, glacier change contributes a considerable amount (40-90\%) of uncertainty to the hydrological projections in summer. With respect to total runoff, the variation of forest cover is negligible. Forest change is always important, however, as long the evapotranspiration is considered, and the variance fraction is proportional to the change in forested area.

\section{Discussion}

The results presented in the previous section will be compared to existing studies that analysed the effects of glacier or forest change on projected hydrological change. Furthermore, the findings as well as the applied methods will be critically reflected and possible extensions of the study will be discussed.

Regarding total runoff, the impact of forest change was mostly small to negligible. The runoff is reduced when forest area increases, but in most cases this reduction does not compare to the change introduced through climate change. This result is supported by studies from Zierl and Bugmann (2005) and Gasser et al. (2003) who also found only minor impacts of a changed land cover on projected runoff. Gasser et al. (2003) studied climate induced land cover changes in the Thur catchment; our case studies 2 and 3 are situated within this pre-alpine catchment in north-eastern Switzerland. They assumed a forest growth on arable land above $1000 \mathrm{~m}$ a.s.l. in general and found that the runoff is reduced. The reduction, however, is of subordinate importance compared to runoff changes introduced through climate change. Zierl and Bugmann (2005) tested forest scenarios that account for a tree line increase at higher elevations, but also for deforestation at lower altitudes, which mostly resulted in decreasing forest area at the catchment scale in the scenario period. Still, the results are comparable to our findings, because they found that the projected runoff increases when forest area decreases. So, this is the same relationship of forest change and projected hydrological change that we found. For extreme scenarios with forest increases of more than $35 \%$ of the catchment area, the net effect on actual summer evapotranspiration caused by the forest change is larger than that caused by the climate scenarios alone (e.g., $-5 \%$ for $\mathrm{CC}$ opposed to $+3 \%$ for $\mathrm{FC}_{1},+5 \%$ for $\mathrm{FC}_{2},+4 \%$ for $\mathrm{FC}_{3}$ ).

Glacier retreat, in contrast to forest change, has a discernible influence on annual runoff and significantly alters the summer runoff in catchments that are moderately to highly glaciated $(>10 \%)$ during the control period. This is supported by studies from Huss et al. (2008), Jost et al. (2012) and Stahl et al. (2008). All three studies compared the projected runoff of a static glacier area under changed climate conditions to the runoff projection if the glacier area is adjusted to the altered climate. In our study, this is the comparison of $\mathrm{CC}_{\mathrm{EM}}$ (climate change and control period glacier extent) to $\mathrm{GC}_{\mathrm{EM}}$ (climate change and glacier retreat), or in other words the net effect of $\mathrm{GC}_{\mathrm{EM}}$. Jost et al. (2012) and Stahl et al. (2008) found that the projected summer runoff would be overestimated with a static glacier by roughly $50 \%$ at the end of the 21 st century, although they considered catchments with very different glaciations in the control period (6\% and $62 \%)$. Huss et al. (2008) even found an overestimation of $100 \%$. In our study, the strongest glaciation in the control period is $51 \%$ and the associated overestimation of summer runoff when not accounting for glacier retreat would be $22 \%$. This value is small compared to the cited studies and indicates that our glacier scenarios are rather conservative as stated earlier.

The third type of scenarios, climate change, proved to be the most important driver of hydrological change in this study, by far, and dominates the changes in the target variables to a large extent. This was demonstrated by the analysis of net changes. Regarding total runoff, the climate scenario proved to be the most important source of uncertainty in the analysis of variance, too. Considering that we sampled just a certain portion of that uncertainty (only one emission scenario was applied) the total uncertainty introduced through climate change is very likely higher than our results suggest. The finding that the climate scenario is the most important source of uncertainty in hydrological climate impact studies is supported by several recent studies, for example, Bosshard et al. (2012), Finger et al. (2012), Horton et al. (2006) and Schaefli et al. (2007). Although those studies compared the importance of climate model uncertainty to that of the emission scenario (Horton et al., 2006), to the hydrological model structure (Schaefli et al., 2007) as well as the downscaling method (Bosshard et al., 2012) and to different glacier scenarios as well as model parameter uncertainty (Finger et al., 2012), we still compare them to our results. We justify this by the fact that the climate model was the dominant uncertainty source in all cited studies, regardless of the very different kind of uncertainty sources the climate model was compared to.

It has to be stated that the importance of glacier and forest cover change could be different, however, if the applied climate scenarios would account for feedbacks between the land cover and the climate. Smith et al. (2011) found, for example, that the lowering of the albedo through projected increases of the tree line in an alpine environment would lead to a positive feedback on the climate system, which means that the temperature increase would be intensified. Another study (Cox et al., 2000) showed that the vegetation in general would act as a carbon sink until 2050, but turn into a source in the second half of the 21 st century which also implies an intensified temperature increase, and which in turn would further alter the land cover. The soil moisture is another important variable influencing summer climate variability through feedbacks with precipitation and temperature 
(Seneviratne et al., 2006). The climate scenarios applied in the present study do not account for feedbacks between the climate and the land cover, however, and our results, therefore, show only the one-way (i.e., the top-down) effects of climate change and altered glacier and forest cover on the hydrology.

In the following, we discuss the validity of our results with respect to the forest scenarios. Our forest change scenarios represent a possible future forest extent under perfectly favourable growing conditions. The scenario tree lines in our study are, therefore, very likely too high, or, in other words, the increase in forest extent is too extreme. As Henne et al. (2011) argued it is unlikely that trees rapidly grow beyond historic tree lines, i.e., above $2550 \mathrm{~m}$ a.s.l., where soils are mostly undeveloped. Though, our maximum projected scenario tree line is at $2870 \mathrm{~m}$ a.s.l. Besides, several additional changes of environmental factors are expected to determine tree line, such as rising $\mathrm{CO}_{2}$ concentrations, increasing deposition of nitrogen (Grace et al., 2002) and soil water availability (Henne et al., 2011). Regarding the aspect of water availability, another important feature that was not accounted for is the change in precipitation; the forest scenarios solely depend on temperature increase. Enhanced drought stress in summer caused by decreasing precipitation, however, could lead to a decline of forests, especially in the dry inneralpine valleys (Dobbertin et al., 2006). Moreover, we neglected natural hazards like avalanches or mudflows which actually play an important role for the distribution of forests in high alpine regions (Theurillat and Guisan, 2001). All mentioned factors would be limiting rather than favourable for tree growth. Some authors (see e.g., Theurillat and Guisan, 2001) would, furthermore, anticipate an altitudinal shift of whole vegetation belts rather than an increase of the upper tree line, only. A shift, however, would lead to decreasing forest areas in the scenarios. For all those reasons, our forest change scenarios are extreme. Considering that, the runoff changes provoked by the forest scenarios are already at the maximum level, but nevertheless insignificant.

One could argue, of course, that another hydrological model that is able to represent flexible feedbacks between the plant and the hydrology, i.e., a flexible growing season, for example, would yield different results regarding the impact of forest change. Another possible improvement would be to couple a landscape evolution model (e.g., Lischke et al., 2006) to the hydrological model which would allow a more physically based distribution of forested area under a future climate. We showed, however, that the influence of forest change can be mainly attributed to its alteration of evapotranspiration. Evapotranspiration and its change, however, are of minor importance in the studied altitudinal range, which is the reason for the minor importance of forest change for the projected runoff.

Another aspect of the hydrological model that should be critically reflected is parameter uncertainty. If the tuneable parameters of the hydrological model could be calibrated on runoff of future climate and land cover states, then the parameter set is likely to be different from the one calibrated on the control period conditions. This is why assessing model parameter uncertainty is crucial, especially when using the model for climate impact analysis and when studying land cover change. For several reasons, however, this assessment could not be included in the present study. For example, the study analysed 15 representative case studies taken from a set of 186 catchments in Switzerland (Köplin et al., 2012; cf. Sect. 2). The model parameters for this extensive set of catchments were regionalised because most alpine catchments in the study domain could not be calibrated on measured natural runoff. The regionalisation procedure, however, entails that the resulting hydrographs cannot be referred to one distinct parameter set anymore (for details please see the description in Sect. 2 and Viviroli et al., 2009c), which makes it impossible to assess parameter uncertainty in this study. Or put another way, we decided to analyse a variety of different catchment types at the expense of assessing model parameter uncertainty. A common way to sample parameter uncertainty is to generate 10000 random parameter sets to run the model and to evaluate these so-called Monte Carlo runs for their goodness of fit. This goes far beyond the means, however, when using a semi-distributed hydrological model like PREVAH and when studying a range of different catchments rather than a single case study. Moreover, applying 10 or 100 equally good parameter sets out of the 10000 does not at all guarantee that those parameter sets are better suited for climate and land cover change modelling. Other studies showed that model parameter uncertainty is less important than climate model uncertainty (e.g., Finger et al., 2012; Schaefli et al., 2007). Finger et al. (2012) also showed that it is less important than the uncertainty related to glacier change in catchments where glaciers substantially contribute to total runoff. It is, however, likely that model parameter uncertainty is more important for the projected runoff than is the uncertainty related to forest change. In summary, we had to exclude hydrological model parameter uncertainty from this analysis in favour of assessing a wide range of different catchment types. The presented results are nevertheless valid, because they evaluate and rank the importance of climate, glacier and forest change, which was the intention of this analysis. It was not sought to conduct a comprehensive uncertainty analysis of the whole hydrological climate impact modelling-chain.

\section{Conclusions}

There is a growing consensus that hydrological climate impact studies should integrate scenarios of associated land cover change to reliably assess future water availability. We developed different scenarios of forest change that are based on the temperature increase of the climate scenarios used in this study. We applied those forest scenarios to extend 
an earlier climate impact study (Köplin et al., 2012) that incorporated scenarios of glacier retreat, already. The relative influence of forest change on the hydrological projections was assessed and compared to the relative influence of glacier retreat and to that of climate change. Through an ANOVA, we analysed the respective variance fractions that can be attributed to the variation (i.e., the uncertainty) within each type of scenario (climate, glacier, forest). This was assessed with respect to changes in actual evapotranspiration, soil moisture storage and total runoff.

Our findings suggest that, at any rate, it is obligatory to apply an ensemble of climate scenarios because the climate scenarios introduced the largest variation of the projected runoff. This finding is particularly true considering that we only assessed one emission scenario. If the runoff of a catchment with a distinct glaciation ( $>10 \%$ in the control period) is analysed in the context of climate change, the accompanying glacier retreat has to be accounted for, too. If no such retreat scenario is available, the relative contribution of glacier melt to the total runoff has to be quantified, at least, for example by removing all glaciers from the catchment and evaluating the resulting changes in runoff. Thus, one can estimate the maximum error that is introduced to the projections by neglecting glacier retreat. The net impact of climate-induced changes in forest cover highly depends on the target variable considered. As long as total runoff is concerned, the forest cover likely has a very minor impact on the projections and can be neglected for the catchments studied here. Though, the projections of evapotranspiration or soil moisture can be altered significantly through forest change. The degree of this change is a function of the degree of forest change.

These findings only apply to hydrological projections under mid-latitude, humid climate conditions and in a mountainous environment where precipitation exceeds evapotranspiration by far (altitudinal range: 1000 to $2600 \mathrm{~m}$ a.s.l.). Furthermore, they are only valid for the projections of mean flow conditions as analysed here. The net effect of land cover can be different if low or high flow conditions are concerned. An interesting extension of this study would, therefore, be to apply the proposed setup, but in another climate region, for example, a more continental area or to assess the impact of the climate-induced land cover scenarios on projected low or high flows. This would complete the picture we established here.

\section{Supplementary material related to this article is available online at: http://www.hydrol-earth-syst-sci.net/ 17/619/2013/hess-17-619-2013-supplement.zip.}

Acknowledgements. This study is funded by the Swiss Federal Office for the Environment (FOEN) in the framework of the joint research project "Climate Change in Switzerland - Hydrology" (CCHydro). The authors would like to thank the FOEN, the Swiss Federal Statistical Office (SFSO) and the Federal Office for Meteorology and Climatology (MeteoSwiss) for providing the necessary input data. The delta change scenario data were distributed by the Center for Climate Systems Modeling (C2SM). The data were derived from regional climate simulations of the EU FP6 Integrated Project ENSEMBLES (Contract number 505539) whose support is gratefully acknowledged. The dataset has been prepared by Thomas Bosshard at ETH Zurich, partly funded by swisselectric/Swiss Federal Office of Energy (SFOE) and $\mathrm{CCHydro/Swiss} \mathrm{Federal} \mathrm{Office} \mathrm{for} \mathrm{the} \mathrm{Environment} \mathrm{(FOEN).} \mathrm{The}$ authors would like to thank Frank Paul and Andreas Linsbauer, Institute of Geography, University of Zurich (GIUZ), for providing the scenarios of glacier retreat.

Edited by: M. Weiler

\section{References}

Arendt, A. A., Echelmeyer, K. A., Harrison, W. D., Lingle, C. S., and Valentine, V. B.: Rapid Wastage of Alaska Glaciers and Their Contribution to Rising Sea Level, Science, 297, 382-386, doi:10.1126/science.1072497, 2002.

Bosshard, T., Kotlarski, S., Ewen, T., and Schär, C.: Spectral representation of the annual cycle in the climate change signal, Hydrol. Earth Syst. Sci., 15, 2777-2788, doi:10.5194/hess-15-27772011, 2011.

Bosshard, T., Carambia, M., Görgen, K., Kotlarski, S., Krahe, P., Zappa, M. and Schär, C.: Quantifying uncertainty sources in an ensemble of hydrological climate-impact projections, Water Resour. Res., doi:10.1029/2011WR011533, in press, 2012.

Bronstert, A.: Rainfall-runoff modelling for assessing impacts of climate and land-use change, Hydrol. Process., 18, 567-570, doi:10.1002/hyp.5500, 2004.

CH2011: Swiss Climate Change Scenarios CH2011, C2SM, MeteoSwiss, ETH, NCCR Climate, and OcCC, Zürich, Switzerland, ISBN: 978-3-033-03065-7, 88 pp., 2011.

Cox, P., Betts, R., Jones, C., Spall, S., and Trotterdell, I.: Acceleration of global warming due to carbon-cycle feedbacks in a coupled climate model, Nature, 408, 184-187, 2000.

Cuo, L., Lettenmaier, D. P., Alberti, M., and Richey, J. E.: Effects of a century of land cover and climate change on the hydrology of the Puget Sound basin, Hydrol. Process., 23, 907-933, doi:10.1002/hyp.7228, 2009.

Dobbertin, M., Rigling, A., Graf Pannatier, E., Rebetez, M., and Wohlgemuth, T.: Die Klimaveränderung bedroht die Föhrenwälder im Wallis, 08, 37-39, 2006.

Doncaster, C. P. and Davey, A. J. H.: Analysis of Variance and Covariance, Cambridge University Press, Cambridge, ISBN: 9780511611377, 2007.

Dullinger, S., Dirnböck, T., and Grabherr, G.: Modelling climate change-driven treeline shifts: relative effects of temperature increase, dispersal and invasibility, J. Ecol., 92, 241-252, 2004.

Dunn, S. and Mackay, R.: Spatial variation in evapotranspiration and the influence of land use on catchment hydrology, J. Hydrol., 171, 49-73, 1995. 
Dyurgerov, M. B. and Meier, M. F.: Mass Balance of Mountain and Subpolar Glaciers: A New Global Assessment for 1961-1990, Arctic Alpine Res., 29, 379-391, 1997.

Egli, M., Mirabella, A., and Sartori, G.: The role of climate and vegetation in weathering and clay mineral formation in late Quaternary soils of the Swiss and Italian Alps, Geomorphology, 102, 307-324, doi:10.1016/j.geomorph.2008.04.001, 2008.

Elsner, M. M., Cuo, L., Voisin, N., Deems, J. S., Hamlet, A. F., Vano, J. A., Mickelson, K. E. B., Lee, S.-Y., and Lettenmaier, D. P.: Implications of 21st century climate change for the hydrology of Washington State, Climatic Change, 102, 225-260, doi:10.1007/s10584-010-9855-0, 2010.

Finger, D. C., Heinrich, G., Gobiet, A., and Bauder, A.: Projections of future water resources and their uncertainty in a glacierized catchment in the Swiss Alps and the subsequent effects on hydropower production during the 21 st century, Water Resour. Res., 48, W02521, doi:10.1029/2011WR010733, 2012.

Gasser, D., Hauser, L., Quirici, R., Preuschoff, P., Schläpfer, M., Wegmann, R., Kleinn, J., Verbunt, M., Gurtz, J., Schär, C., and Wehrli, B.: Einfluss von Klima- und Landnutzungsänderungen auf den Abfluss der Thur, Gruppe "Klima und Hydrologie" der Fallstudie Thur, ETH Zürich, WEL, 95, 337-343, 2003.

Gehrig-Fasel, J., Guisan, A., and Zimmermann, N. E.: Tree line shifts in the Swiss Alps: Climate change or land abandonment?, J. Veg. Sci., 18, 571-582, doi:10.1111/j.16541103.2007.tb02571.x, 2007.

Grace, J., Berninger, F., and Bagy, L.: Impacts of Climate Change on the Tree Line, Ann. Bot.-London, 90, 537-544, doi:10.1093/aob/mcf222, 2002.

Gunawardhana, L. N. and Kazama, S.: A water availability and lowflow analysis of the Tagliamento River discharge in Italy under changing climate conditions, Hydrol. Earth Syst. Sci., 16, 10331045, doi:10.5194/hess-16-1033-2012, 2012.

Gurtz, J., Baltensweiler, A., and Lang, H.: Spatially distributed hydrotope-based modelling of evapotranspiration and runoff in mountainous basins, Hydrol. Process., 13, 2751-2768, 1999.

Hänggi, P.: Auswirkungen der hydroklimatischen Variabilität auf die Wasserkraftnutzung in der Schweiz, PhD Thesis, Faculty of Science, University of Bern, Berne, Switzerland, 206 pp., 2011.

Harsch, M. A., Hulme, P. E., McGlone, M. S., and Duncan, R. P.: Are treelines advancing? A global meta-analysis of treeline response to climate warming, Ecol. Lett., 12, 1040-1049, doi:10.1111/j.1461-0248.2009.01355.x, 2009.

Hejazi, M. I. and Moglen, G. E.: The effect of climate and land use change on flow duration in the Maryland Piedmont region, Hydrol. Process., 22, 4710-4722, doi:10.1002/hyp.7080, 2008.

Henne, P. D., Elkin, C. M., Reineking, B., Bugmann, H., and Tinner, W.: Did soil development limit spruce (Picea abies) expansion in the Central Alps during the Holocene? Testing a palaeobotanical hypothesis with a dynamic landscape model, J. Biogeogr., 38, 933-949, doi:10.1111/j.1365-2699.2010.02460.x, 2011.

Horton, P., Schaefli, B., Mezghani, A., Hingray, B., and Musy, A.: Assessment of climate-change impacts on alpine discharge regimes with climate model uncertainty, Hydrol. Process., 20, 2091-2109, 2006.

Hundecha, Y. and Bárdossy, A.: Modeling of the effect of land use changes on the runoff generation of a river basin through parameter regionalization of a watershed model, J. Hydrol., 292, 281-295, doi:10.1016/j.jhydrol.2004.01.002, 2004.
Huss, M., Farinotti, D., Bauder, A., and Funk, M.: Modelling runoff from highly glacierized alpine drainage basins in a changing climate, Hydrol. Process., 22, 3888-3902, doi:10.1002/hyp.7055, 2008.

Jost, G., Moore, R. D., Menounos, B., and Wheate, R.: Quantifying the contribution of glacier runoff to streamflow in the upper Columbia River Basin, Canada, Hydrol. Earth Syst. Sci., 16, 849-860, doi:10.5194/hess-16-849-2012, 2012.

Klöcking, B. and Haberlandt, U.: Impact of land use changes on water dynamics - a case study in temperate meso and macroscale river basins, Phys. Chem. Earth, 27, 619-629, 2002.

Köplin, N., Viviroli, D., Schädler, B., and Weingartner, R.: How does climate change affect mesoscale catchments in Switzerland? - a framework for a comprehensive assessment, Adv. Geosci., 27, 111-119, doi:10.5194/adgeo-27-111-2010, 2010.

Köplin, N., Schädler, B., Viviroli, D., and Weingartner, R.: Relating climate change signals and physiographic catchment properties to clustered hydrological response types, Hydrol. Earth Syst. Sci., 16, 2267-2283, doi:10.5194/hess-16-2267-2012, 2012.

Körner, C.: A re-assessment of high elevation treeline position and their explanation, Oecologia, 115, 445-459, 1998.

Körner, C.: The use of "altitude" in ecological research, Trends Ecol. Evol., 22, 569-574, doi:10.1016/j.tree.2007.09.006, 2007.

Laghari, A. N., Vanham, D., and Rauch, W.: To what extent does climate change result in a shift in Alpine hydrology? A case study in the Austrian Alps, Hydrolog. Sci. J., 57, 103-117, doi:10.1080/02626667.2011.637040, 2012.

Lahmer, W., Pfützner, B., and Becker, A.: Assessment of Land Use and Climate Change Impacts on the Mesoscale, Phys. Chem. Earth (B), 26, 565-575, 2001.

Leuzinger, S.: Stand der Kenntnisse zu den Auswirkungen des Globalen Wandels auf Schweizer Wälder, Bericht im Auftrag des Bundesamtes für Umwelt BAFU, Synthesis Report, Bern, Switzerland, 56 pp., http://www.bafu.admin.ch/ wald/01198/01209/index.html?lang=de (last access: 29 November 2012), 2009.

Linsbauer, A., Paul, F., Machguth, H., and Haeberli, W.: Comparing three different methods of modelling scenarios of future glacier change in the Swiss Alps, Ann. Glaciol., 54, accepted, 2013.

Lischke, H., Zimmermann, N. E., Bolliger, J., Rickebusch, S., and Löffler, T. J.: TreeMig: A forest-landscape model for simulating spatio-temporal patterns from stand to landscape scale, Ecol. Modell., 199, 409-420, doi:10.1016/j.ecolmodel.2005.11.046, 2006.

Lüscher, C.: 10 Jahre Sachplan Fruchtfolgeflächen (FFF), Erfahrungen der Kantone, Erwartungen an den Bund, Legislative text, Federal Office for Spatial Development ARE: Bern, Switzerland, 64 pp., 2004.

Mavris, C., Egli, M., Plötze, M., Blum, J. D., Mirabella, A., Giaccai, D., and Haeberli, W.: Initial stages of weathering and soil formation in the Morteratsch proglacial area (Upper Engadine, Switzerland), Geoderma, 155, 359-371, doi:10.1016/j.geoderma.2009.12.019, 2010.

MBB: Glacier Mass Balance Bulletin No. 8, in: World Glacier Monitoring Service on behalf of IUGG (CCS)/UNEP/UNESCO/WMO, WGMS, edited by: Haeberli, W., Noetzli, J., Zemp, M., Baumann, S., Frauenfelder, R., and Hoelzle, M., Zurich, 100 pp., 2005. 
Monteith, J. L.: Vegetation and the atmosphere, Vol. 1: Principles, Academic Press, London (UK), 298 pp., 1975.

Paul, F., Kääb, A., Maisch, M., Kellenberger, T., and Haeberli, W.: Rapid disintegration of Alpine glaciers observed with satellite data, Geophys. Res. Lett., 31, L21402, doi:10.1029/2004GL020816, 2004.

Paul, F., Maisch, M., Rothenbühler, C., Hoelzle, M., and Haeberli, W.: Calculation and visualisation of future glacier extent in the Swiss Alps by means of hypsographic modelling, Global Planet. Change, 55, 343-357, doi:10.1016/j.gloplacha.2006.08.003, 2007.

Paul, F., Linsbauer, A., and Haeberli, W.: Grossräumige Modellierung von Schwundszenarien für alle Schweizer Gletscher, Klimaänderung und Wasserkraft, Sektorielle Studie Wallis, Modul B Gletscherszenarien, Final Report, University of Zurich, Zurich, 29 pp., 2011.

R Development Core Team: R: A language and environment for statistical computing, R version 2.14.1, R Foundation for Statistical Computing, Vienna, Austria, ISBN: 3-900051-07-0, http: //www.R-project.org/ (last access: 29 November 2012), 2011.

Rössler, O., Diekkrüger, B., and Löffler, J.: Potential drought stress in a Swiss mountain catchment - Ensemble forecasting of high mountain soil moisture reveals a drastic decrease, despite major uncertainties, Water Resour. Res., 48, W04521, doi:10.1029/2011WR011188, 2012.

Schaefli, B., Hingray, B., and Musy, A.: Climate change and hydropower production in the Swiss Alps: quantification of potential impacts and related modelling uncertainties, Hydrol. Earth Syst. Sci., 11, 1191-1205, doi:10.5194/hess-11-11912007, 2007.

Schumacher, S. and Bugmann, H.: The relative importance of climatic effects, wildfires and management for future forest landscape dynamics in the Swiss Alps, Global Change Biol, 12, 1435-1450, doi:10.1111/j.1365-2486.2006.01188.x, 2006.

Seneviratne, S. I., Lüthi, D., Litschi, M., and Schär, C.: Landatmosphere coupling and climate change in Europe, Nature, 443, 205-209, doi:10.1038/nature05095, 2006.

Smith, B., Samuelsson, P., Wramneby, A., and Rummukainen, M.: A model of the coupled dynamics of climate, vegetation and terrestrial ecosystem biogeochemistry for regional applications, Tellus, 63, 87-106, doi:10.1111/j.16000870.2010.00477.x, 2011.

Stahl, K., Moore, R. D., Shea, J. M., Hutchinson, D., and Cannon, A. J.: Coupled modelling of glacier and streamflow response to future climate scenarios, Water Resour. Res., 44, W02422, doi:10.1029/2007WR005956, 2008.

Theurillat, J.-P. and Guisan, A.: Potential impacts of climate change on vegetation in the European Alps: a review, Climatic Change, 50, 77-109, 2001.
Tinner, W. and Kaltenrieder, P.: Rapid responses of highmountain vegetation to early Holocene environmental changes in the Swiss Alps, J. Ecol., 93, 936-947, doi:10.1111/j.13652745.2005.01023.x, 2005.

Tinner, W. and Lotter, A. F.: Central European vegetation response to abrupt climate change at $8.2 \mathrm{ka}$, Geol, 29, 551-554, doi:10.1130/0091-7613(2001)029<0551:CEVRTA > 2.0.CO;2, 2001.

Tinner, W. and Theurillat, J.-P.: Uppermost Limit, Extent, and Fluctuations of the Timberline and Treeline Ecocline in the Swiss Central Alps during the Past 11,500 Years, Arct. Antarct. Alp. Res., 35, 158-169, 2003.

van der Linden, P. and Mitchell, J.: ENSEMBLES: Climate Change and its Impacts: Summary of research and results from the ENSEMBLES project, FitzRoy Road, Exeter EX1 3PB, UK, 160 pp., 2009.

Viviroli, D., Gurtz, J., and Zappa, M.: The Hydrological Modelling System PREVAH, Part II - Physical Model Description, Geographica Bernensia P40, Institute of Geography, University of Bern, Switzerland, ISBN:978-3-905835-01-0, 87 pp., 2007.

Viviroli, D., Zappa, M., Gurtz, J., and Weingartner, R.: An introduction to the hydrological modelling system PREVAH and its preand post-processing-tools, Environ. Modell. Softw., 24, 12091222, doi:10.1016/j.envsoft.2009.04.001, 2009a.

Viviroli, D., Zappa, M., Schwanbeck, J., Gurtz, J., and Weingartner, R.: Continuous simulation for flood estimation in ungauged mesoscale catchments of Switzerland - Part I: Modelling framework and calibration results, J. Hydrol., 377, 191207, doi:10.1016/j.jhydrol.2009.08.023, 2009b.

Viviroli, D., Mittelbach, H., Gurtz, J., and Weingartner, R.: Continuous simulation for flood estimation in ungauged mesoscale catchments of Switzerland - Part II: Parameter regionalisation and flood estimation results, J. Hydrol., 377, 208-225, doi:10.1016/j.jhydrol.2009.08.022, 2009c.

Viviroli, D., Archer, D. R., Buytaert, W., Fowler, H. J., Greenwood, G. B., Hamlet, A. F., Huang, Y., Koboltschnig, G., Litaor, M. I., López-Moreno, J. I., Lorentz, S., Schädler, B., Schreier, H., Schwaiger, K., Vuille, M., and Woods, R.: Climate change and mountain water resources: overview and recommendations for research, management and policy, Hydrol. Earth Syst. Sci., 15, 471-504, doi:10.5194/hess-15-471-2011, 2011.

WaG: Bundesgesetz über den Wald, 921.0, Legislative text, Bundesversammlung der schweizerischen Eidgenossenschaft, 18 pp., http://www.admin.ch/ch/d/sr/9/921.0.de.pdf (last access: 29 November 2012), 2008.

Zierl, B. and Bugmann, H.: Global change impacts on hydrological processes in Alpine catchments, Water Resour. Res., 41, W02028, doi:10.1029/2004WR003447, 2005. 